\title{
Little Steps at Improving Preschool Teachers Practices through Counseling Skills in Qatar
}

\author{
Aisha Al-Thani ${ }^{1} \&$ Ramzi Nasser ${ }^{2}$ \\ ${ }^{1}$ Department of Psychological Sciences, Qatar University, Qatar \\ ${ }^{2}$ Department of Educational Sciences, Qatar University, Qatar \\ Correspondence: Ramzi Nasser, Qatar University, POBOX 2713 Doha, Qatar. Tel: 974-6605-7952. E-mail: \\ ramzin@qu.edu.qa
}

Received: May 24, 2012 Accepted: June 11, $2012 \quad$ Online Published: August 23, 2012

doi:10.5539/ies.v5n5p163 URL: http://dx.doi.org/10.5539/ies.v5n5p163

\begin{abstract}
The study focused on the effects of basic counseling skills program, such as listening, understanding, respecting, and empathizing, to elementary school teachers in Qatar. Through a three-hour intervention program, the authors used a self-reported questionnaire, interview questions and classroom observations to examine changes in how preschool teachers' dealt with students' in the classroom. Our findings suggest basic counseling skills had an impact on teachers as it encouraged them to understand terms such as "counseling," which basic counseling skills had allowed teachers to improve the quality of students-teacher relationships and their relationships with others. Teachers became aware of their practices as reflective practitioners to improve their practice.
\end{abstract}

Keywords: counseling skills, pre-school, Qatar, teacher training

\section{Introduction}

Qatar is a small nation state that is one of the Gulf Cooperation Council (GCC) countries. It enjoys one of the highest per capita based on its Gross Domestic Products in the world. According to the Central Intelligence Agency (2009), Qatar is recognized as the world's second wealthiest country and has acquired its wealth through oil and gas. Through that wealth, Qatar has invested in a knowledge-based economy (Al-Sulayti 1999), with a focus on its educational sector. This focus in 2001 led to what is known as Qatar's educational reform (Education For a New Era (EFNE)), which has changed the educational landscape. A key aspect of the reform has been to improve the quality of teachers and school leaders.

Since the beginning of the reform, the Supreme Education Council (SEC) (equivalent to the UK's Department for Education or the US's Department of Education) has introduced the following reforms: a) revised curriculum standards, b) national professional standards for teachers and school leaders, c) education support for professionals, d) an enhanced program of professional learning for staff employed in schools, and e) the first registration and licensing of teachers and school leaders in the GCC countries. Despite these reforms and the modern approaches to educational practices, few guidelines related to teacher standards or practices inform the stakeholders and teachers about counseling skills. The assumption, and the basis of this study, is that knowledge of counseling skills is an essential element in teacher education, as it affects student learning and wellbeing (Hutchins \& Vaught, 1997). Teachers play a significant role in resolving student issues and concerns, and they provide the necessary social and emotional skills, such as problem solving, communication, responsibility, and empathy, that allow students to be academically successful (Elias \& Weissberg, 2000). When this intervention begins in early grades (Lane, Gresham, \& O'Shaughnessy, 2002), it can have a long-term impact on students' social and psychological wellbeing and makes teachers an essential resource for students (Kline \& Silver, 2004) and school systems (Wong, Rosemond, Stein, Langley, Kataoka, \& Nadeem, 2007). Many parents may find it difficult to seek support outside school, because of concerns about family honor and status in a country with close-knit extended families (Farsoun, 1985). Even when parental support is most needed (Berry, 1987), parents are often unable to seek support, and teachers are unprepared to deal with students' social and emotional needs (Pavri \& Hegwer-DiVita, 2006; Schnitzer, Andries, \& Lebeer, 2007). Despite being expected to recognize signs of emotional instability, special needs or even abuse (Kottler \& Kottler, 1993; Pirtle \& Perez, 2003), teachers do not have the faculties to deal with students' growing needs (Matthews and Menna, 2003). Thus, teachers are in desperate need of training in counseling and guidance for the social and emotional needs of at-risk youths (Christensen, Young, \& Marchant, 2007). 
Another consideration of this study is that standards in Qatar aim to create an educational environment where children are given the opportunity to develop and prosper at all stages of their educational life and through actual life experiences. Counsellors' and teachers' roles in assisting student academic, social, personal and career development have been generally limited. We make these observations on the basis of our own experiences as classroom educators and through our research in Qatar schools. In some Eastern cultures, such as Jordan (Ammari 2004; Alsmadi \& Mahasneh, 2011) and Hong Kong (Lam \& Hui, 2010), teachers and counselors have little understanding of their roles as counselors, and there is little support for those roles in the schools. The primary author acquired extensive experience as a school counselor before the completion of her PhD. She found a lack of guidance clearly exists in some of the preschool and independent school teachers in the State of Qatar. The first author inquired about methods and techniques for dealing with children's needs and building healthy relationships between students and teachers. Moreover, we believe awareness of basic counseling skill helps improve the quality of relationship with self and with others.

In this era of accountability, many teachers, not only in Qatar, but also all over the world are overstrained by the curriculum and teacher standards and are under pressure to meet academic goals and standards (Nasser \& Romanowski, 2011; Mayer, Lochman, \& Van Acker, 2005). Even with a subject-focus in curriculum design, teachers are finding it difficult to integrate guidance and counseling skills in practice (Watts \& Kidd, 2000). Teachers are given little knowledge of intervention strategies in pre-service courses (Schnitzer, Andries, \& Lebeer, 2007) or later in their careers (Ashman, 2003). As early as 1952, Williams stressed the role of counseling and other types of therapy required to deal with personal problems. The National Professional Qatari Standards for Teachers and School Leaders in Qatar underlines the idea that teachers and school leaders are strengthened by a commitment to creating and fostering safe, supportive and challenging learning environments. Therefore, learning and applying basic counseling skills is important to prevent and avoid psychological problems and to improve effective teacher practices.

The application of basic counseling skills by preschool teachers is something new in the Qatari educational environment, presenting a challenge for those concerned with the preschool educational system, including parents, school leaders and especially teachers.

In an Islamic society like Qatar, little is known about teachers' understanding of counseling skills. The first author of this manuscript, inquired about methods and techniques for dealing with children's needs, and we found that teachers generally have little knowledge of these skills. Moreover, we believe that awareness of some basic counseling skills could improve the quality of the relationships with students and teachers. One reason that such skills have been predominantly not brought to attention to schools, is because of cultural imperative in which Islamic collectivist-humanistic operates; a close-knit society is believed to act as a cushion to the psychological needs of children. But with the modernization of cultural life of Qataris, the sense of family cohesion has weathered at home thus leaving the child nowhere to go, neither to seek help at school or at home. Such issue perceived from a Judeo-Western perspective is approached through an individualist-humanistic dimension when dealing with children through one-to-one counseling approaches. We did however perceive such skills within collective Islamic conscious as we developed the workshop for teachers.

From this perspective, basic counseling skills that focus on listening and understanding, acceptance and empathy being important in changing teacher behavior and improving teacher practices. These skills were presented in a three-hour workshop and described below.

\subsection{Listening and Understanding}

Listening is considered to be the most important skill to teach people on how to interact with others. Providing this skill at the preschool level helps children learn communication skills from an early age.

Listening also helps the preschool teacher build healthy teacher-child relationships based on mutual respect. Children need to be listened to at this age. They share their real life experiences with others, including their teacher. Listening encourages preschool children to listen to each other and addresses their needs.

\subsection{Acceptance}

Accepting children helps them feel loved and respected by their teachers. Children who seek help are taught what is acceptable and unacceptable behavior in a loving and caring way. Rogers' (1961) work suggests that accepting others helps to build strong relationships and secures the child in a warm and safe environment. Counselors have often used verbal reinforcements, such as word 'prizing,' to help students feel safe. Teachers must also develop sincere caring skills recognized by the students for students to feel liked and safe. 


\subsection{Empathy}

Empathy is required because children want to feel that their teacher is able to understand their needs and their perspective. Empathy involves a considerable depth of understanding of and emotional engagement with the child's world (Mearns \& Cooper, 2005). Merry (2004) states that it is a way of understanding the internal world and trying to capture something of the feelings of people's experiences without judging them. Preschool teachers play a crucial role in the individual development of children and in integrating them with society. Teachers with high empathy skills affect children's development positively.

Thus, this study examined the effectiveness of applying basic counseling skills among preschool teachers at independent schools in the state of Qatar. We addressed the following research question to get to the answers.

1) Would the preschool teachers benefit from training and short intervention programs?

2) Would they apply basic counseling skills when dealing with children?

3) Would the teachers be more aware of their own needs as individuals after the workshop?

\section{Method}

\subsection{Procedure}

A case study approach that included a questionnaire, interview and classroom observation was conducted. We examined several cases over time to collect data from multiple sources of information (e.g., questionnaires, interviews and observations) (Palmer, El-Ashry, Leclere, \& Chang, 2007). The data we collected abled us to mark teacher beliefs and practices in a natural setting and the intra-subject understanding generated a detailed case description and case-based themes (Feagin, Orum \& Sjoberg, 1991).

Hence, in view of the absence of research on teacher counseling skills in Qatar, a case study approach was deemed sufficient for an exploratory study of the present research. Teachers were administered a questionnaire-interview and were later observed for a quarter of an hour during a teaching session. As McLeod (2003) commented: "In case study research, the notion of combining qualitative and quantitative data is attractive. It offers the promise of getting closer to the "whole' case in a way that a single-method study could never do." (p.108). The use of this combination of methods helped us to exploit the strengths of each data source.

Three questions were formulated to measure the teachers' basic knowledge of counseling skills. The three questions were administered before the workshop training and were administered again in a post-training session. The pre- and post-questionnaire asked teachers how they would rate their teaching skills, self-relationship and relationship with others. The teachers were asked to answer a questionnaire before the workshop and then complete an interview questionnaire after the workshop. The interview questionnaire was based on the three dimensions: listening and understanding, acceptance and empathy. Once the information was collected from the three teachers, an intervention workshop was conducted to address some of the challenges in counseling skills. After the workshop was held, the same open-ended interview questions were administered and class observations were made.

The interview question items assessed the teachers' knowledge of basic counseling skills and methods for dealing with the preschool students' needs and requirements. The questionnaire's face validity was addressed by a psychologist working at a local hospital in Qatar. The psychologist was asked to confirm that the questions were clear and that they met the purpose of the study. The questions were then revised by the authors for trustworthiness, applicability and appropriateness.

\subsection{Participants}

The study sample consisted of three preschool teachers between the ages of 26 and 35, who had at least five years of experience working in Qatari independent schools. They attended a workshop in early 2011 at the national university in Qatar. The teachers volunteered to be part of the study. They attended the workshop and were then visited and observed at their school during the 2011-2012 academic years. The teachers were observed equally by a research assistant and by one of the authors.

All the participating teachers were willing to attend the workshop. They were interested in relating the workshop information to both their careers and their real life experiences. The forms reflected some progress and changes from before and after the workshop.

\subsection{Ethical Considerations of Our Work with Preschool Teachers}

The researchers felt that it was their responsibility to protect the participants and to ensure that they felt comfortable working with the researchers. We wanted teachers to feel free, comfortable and open to express their 
feelings and thoughts about continuing in the study. Referring to Bowling (2002), we allowed the teachers the freedom to continue or dropout from the study at any time.

The three teachers were asked to sign an informed consent form before participating in the study. Informed consent is one of the main strategies used for ensuring that ethical principles are reflected in practice. As McLeod (2009) suggests: "The informed consent form mainly involved providing the teachers with the accurate and adequate information about the case study interviews. The three teachers were then allowed sufficient time to make up their own mind, and offered an opportunity to ask questions, then make a decision that forms a contract or binding agreement between himself or herself and the therapist." (p.518)

\section{Findings}

The first analysis of the study evaluated three items: a self-reporting questionnaire, post-training interview questions and class observations. Both sources of information were used to address whether teachers integrated basic counseling skills into the classroom.

\subsection{Self-reporting Questionnaires}

Self-reporting questionnaires are widely used in research (McLeod, 2003). The advantage of the questionnaires is that they are easy to administer and interpret. Teachers were asked to respond to the following three questions before and after the intervention workshop. These questions were provided on a ten-point Likert ("low" $=0$ to "high"=10) scale.

How would you evaluate your teaching skills?

Evaluate your self-relationship before with others.

Evaluate your relationship with others.

The findings use fictitious names for the teachers to keep their identities anonymous.

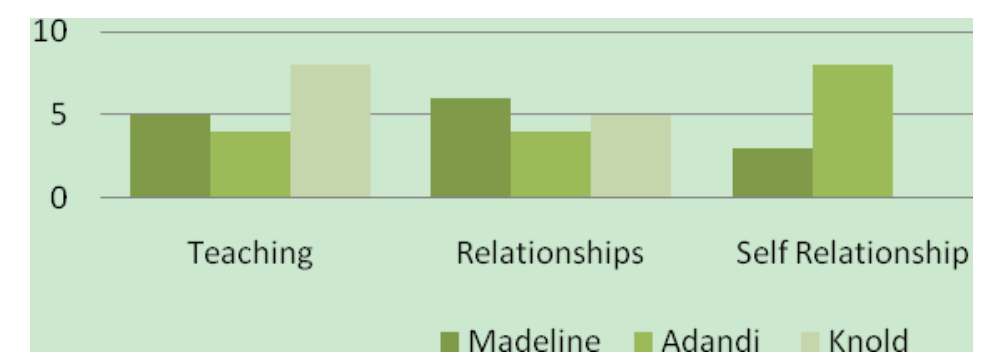

Figure 1. Teachers self-evaluation on the three main dimensions before the intervention

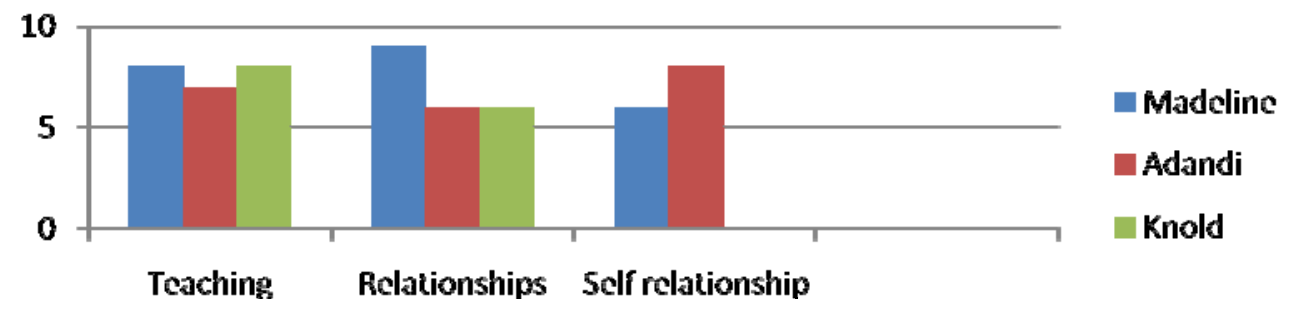

Figure 2. Teachers self-evaluation on the three main dimensions post-workshop intervention

All three participating teachers were willing to attend the workshop. They showed interest in relating the experience to both their careers and their real life experiences.

Figure 1 shows the teachers' self-ratings before the workshop. Figure 2 shows the questionnaire responses after attending the workshop. Overall, two of the teachers reported a certain level of self-improvement whereas Knold 
did not see herself as improving. Although the workshop was only held for a short time-period, the teachers were able to apply some of the counseling skills in their classes.

In Figure 2, the two teachers Adandi and Madeline felt that their teaching had improved by applying the basic counseling skills to the teaching process. Moreover, the quality of teacher relationship with selves and others has shown a substantial growth in the teachers. Knold was aware of the importance of teaching than the other two teachers. When drawing comparisons between the pre- and post-workshop, Madeline's self-perception of her teaching skills improved (see Figure 1), and she rated herself as a nine for self-improvement (see Figure 2). This improvement shows that the teacher became significantly aware of the importance of the self-relationship.

In Figure 2, Madeline's relationship with others was rated the highest. Both Adandi and Knold valued relationships with other equally but showed some positive changes after the workshop in which it improved the relationships with others.

Adandi valued her self-relationship more than the other two teachers. In Knold's case, she rated herself as a five before the workshop and as a six after attending the workshop. Interestingly, Adandi generally self-rated higher the three dimensions post-training and believed strongly in relationship with others.

\subsection{Post-Workshop Interviews with the Preschool Teachers}

The interview provided the researchers with the teachers' views regarding counseling. The interviews also helped to ask open-ended questions, allowing us to collect large amounts of information that did not require writing lengthy answers (Bryman \& Cramer, 2001). Teachers were asked three basic questions: a) What was the benefit of the workshop; b) what was the most important skill you have learned and c) what positive effect did counseling skills has?

The interview showed that the teachers benefited from the workshop. They believed that the workshop helped them to find techniques and skills to improve their teaching, relationship and self-relationship. For example, Knold stated: "Yes, I learned some new counseling skills." Adandi agreed with the statement and added: "Yes, I benefited so much by applying the counseling skill methods in the class environment and in my actual life."

Regarding the teachers' benefits in dealing with students, Madeline indicated: "Yes, I'm satisfied about myself, because I am now aware of my students when they need my assistance. I keep helping and supporting them, and I try to listen to all of them. I am aware that students ask questions all at once. Now, I listen to everyone and do respond to every one so as not to alienate them." Mearns and Thorne (1999) also emphasize the importance of nonverbal communication: "Touching' is a natural and literal reaching out of one human being towards another, but many people in some cultures find it enormously difficult to show their warmth through touch." (p.76)

The teachers also believed that offering time for the students to share their experiences, feelings and thoughts is an important skill that needs to be applied in the school environment.

Madeline said: "Taking the time to listen to them and giving them the chance to express their feelings shows them that I care for what they said. "Encouraging children to express their thoughts and feelings before the session helps children pay more attention to what the teacher says or does during the class. Knold stated: "I understood from the workshop that by providing time at the beginning of the class to listen and talk to my students, based on what we learned in the workshop, provided an opportunity for the children to express their thoughts and feelings."

All the teachers agreed that listening was the most important skill when teaching students. Knold stated: "By listening and talking to the students, loving them, accepting what they say and dealing with them positively..., one accepts the student." Adandi said: "By listening to the students' problems and trying to solve them, caring about the student and giving them sufficient love... as well as observing their behavior during the class, one could reflect and improve one's practice in future." Adandi became reflective and made constructive critiques of her practice. This self-reflection is important for teachers' to improve themselves and their practices. Looking back what they did and think through their actions.

An interesting point was made by Adandi, who believed that the workshop helped her to not only listen to the students but also recognize nonverbal communications from her students. Adandi states: "Yes, I benefited so much by applying knowledge from the workshop in terms of listening and attending to and observing the students."

We also asked what the positive effects were of applying the counseling skills when building a healthy relationship with students. The focus was on the positive features that the teacher-student relationship should have. Some focused on the students' academic progress that would occur through building a healthy relationship. Madeline focused on encouraging students to talk freely and stated that this will help remove obstacles such as timidity and general anxiety that usually cause students stress. Knold said that "we must care about strengthening relationships 
with students," and Adandi stated that a good teacher-student relationship "has a positive impact, as it encourages the student to build a good relationship with the teacher as well."

The teachers believed that a healthy relationship based on understanding and counseling skills helps to improve the quality of teaching and students' performances. Madeline stated: "The teacher is the person at the school who can make a difference in the students' psychological wellbeing." Knold added: "I am now aware of encouraging students to care more about academics." Adandi said: "I think, as a teacher, I have counseling skills. I know how to control the students in class and know about their psychological needs before everything else."

In summary, Madeline said: "I am now aware of dealing with children's problems." She emphasized the importance of attending more workshops on counseling to become closer to others. Madeline stated: "The workshop is necessary for me to have a healthy relationship with myself more than it is needed to help me deal with others. My own problems helped me to feel and understand the children's problems and needs." Knold believed that dealing with children is not easy, as one must provide assistance, understanding and guidance to the children's needs. She also emphasized the importance of offering more counseling workshops to increase teachers' awareness of both themselves and children. Knold was open and willing to understand the children's needs through listening to them and being patient. Knold says: "No doubt there is a need for more workshops, because dealing with children is not easy. We need to help and support them. I would like to take more workshops on counseling and methods for dealing with children." Knold noticed improvement in her teaching skills and her dealings with children. She stated: "There are positive changes. I am more willing to listen to the children, solve their problems and ignore their unwanted behaviors. "She also believed that attending the workshop helped her to encourage children to express their thoughts and feelings .

All the teachers believed that listening and dealing with students' problems in teaching matters helped develop a loving and caring relationship. Thus, building a healthy relationship needs to be supported by offering help and support and by directing the students toward their goals. "The importance of listening: When you are not listening, you are not learning. When you are not listening, you are preventing opportunity. The fact that you do not listen reveals the reality that your mind is closed. When you are not listening, you are preventing [the transfer of knowledge]. When you are not listening, there is nothing new; there are only your reactions. If you wish to live life to its fullest, then istening is (http://www.healthguidance.org/entry/3638/1/The-Importance-Of-Listening.html). Finally, the teachers' answers showed the similarities in their methods for dealing with their students. The answers also showed that the teachers believed in the importance of building a healthy relationship with their students in the class environment.

\subsection{Classroom Observations}

\subsubsection{Madeline}

The observation checklist showed that Madeline was able to communicate with the children. Interestingly, both observers strongly agreed that Madeline was a very good listener, as she encouraged the children to express their thoughts and feelings. We strongly agreed in our observations regarding Madeline's obvious ability with verbal communication. We also noted the use of body language and nonverbal communications. Madeline was obviously trying to show how professional she was not aware of the importance of being close both emotionally and physically to the children. Madeline was a novice and her professional behavior affected her relationship with the children. Preschool children love to communicate verbally, because verbal communication gives them the feeling that they are close to and accepted by their teachers. Moreover, tender tapping or stroking children gently creates a bond and provides a sense of support for children. Merry and Lusty (1993) believe that "warmth is respecting individuals as a unique, worthwhile and valued individual." They stress the importance of rapport as a means of communication through matching the way the client communicates, such as using a similar tone of voice or even body action. Mearns and Thorne (1999) also emphasize the importance of nonverbal communication: 'Touching' is a natural and literal reaching out of one human being towards another, but many workers in some cultures find it enormously difficult to show their warmth through touch." (p.76) In places such as the Middle East, sentiment and peer touching among the youth of same sex groups is a common asexual cultural characteristic that could be easily applied when mentoring and supporting students.

\subsubsection{Adandi}

The researchers agreed that Adandi encouraged the children to express themselves and their thoughts. Adandi was a very good listener, and we both appreciated her listening skills. Adandi was very good at absorbing meanings and information. Her proper use of listening skills helped her to fully understand and accurately communicate with her students. 
In addition, both researchers strongly agreed that the teacher was willing to give more time and attention to children to share their experiences when she encouraged them to work as a team. She focused on the children's positive attitudes, continuously reinforcing, positive behavior and purposely ignoring negative actions.

We also noted that the teacher was aware of using the term "we" to refer to the class and herself as one team. Adandi was willing to work dynamically with the children. We agreed that the teacher was tolerant and a hard worker. She made me feel close to her, and we enjoyed her willingness to communicate and her understanding. Although she did not have any previous training courses, she was an expert in her dealings with children.

\subsubsection{Knold}

Both researchers agreed that Knold was willing to encourage children to talk and express their thoughts and feelings freely. The teacher talked positively and optimistically with the children. We both agreed that the teacher was aware of the importance of nonverbal communications. Regarding Knold's use of oral communication, we were both neutral. We agreed that the teacher used the term "we" to refer to the whole class as one group, and she focused on positive attitudes and encouraged the children to work as a team.

Interestingly, neither researcher observed her empathy acceptance. Watching the videoed sessions for the three teachers, the children appeared to be relaxed and enjoyed the teachers' presence. They did not appear to have a problem with being observed by us. Knold and Adandi were willing to be observed, while Madeline was not completely comfortable. She was worried about being watched or videoed, but she agreed to video the children.

The children demonstrated that the three teachers had positive views. They became positive about listening to and encouraging the children. They also became willing to gain knowledge of new skills and teaching techniques to build healthy relationships with the children.

The three teachers believed that the workshop helped them to become closer to children to listen to their problems, an aspect of their teaching profession of which they have not been aware. Teachers informed us that they were more sensitive to their students and created a general sense of awareness that was possibly missing in the beginning.

Adandi gave the children five minutes at the beginning of each class to talk and share their thoughts and feelings with each other. Adandi felt closer to them, and Knold became more willing to help and solve children's problems. Adandi stated that $95 \%$ of the children were willing to cooperate with her. She also believed that listening helped her give children more space to learn and think.

All three teachers believed that some of the preschool children have challenges in some cases, psychological problems that barred them from fully enjoying their lives; therefore, the teachers believed that counseling support is important. Moreover, they believed that both children and teachers should be offered counseling support whenever they need it. For the teachers, they became conscious of the need to look inwardly before trying to understand and help others.

\section{Discussion}

Qatar is predominantly an Arab and Muslim society. Both authors and the three teachers were of Arab background and function in a Muslim society. We needed to consider guidance, counseling and individual needs in this context. We allude to Al-Rashidi (1995) who, as a Muslim, highlights the importance of encouraging individuals to work within themselves and to take responsibility for themselves as Muslims to change their behavior. In addition, Al-Rashidi considers it essential to love and respect the self, to be able to build self-confidence and to live more satisfactorily. On a more "fundamental" note, Al-Shennawy (2001) disagrees with much of Western psychology, and particularly with elements such as self-actualization, freedom and individualism. In his book Studies in Islamic Guidance to Counseling Therapy (2001), he suggests a method of Islamic counseling based on Islamic teaching and the Holy Quran. In his view, Islam is a complete system for helping Muslims in all aspects of their lives and it is enough for Muslims to rely on this system rather than applying Western methods. Al-Shennawy (2001) stresses that the counseling relationship is a community (Muslim)-based interaction in which Muslim values are implanted. Shennawy suggests that at the heart of counseling in a Muslim community is helping one another, encourage people to be active and take responsibility for their lives as a whole.

As researchers, we were aware of our contextual framework, and the focus of our program was not too diverse from the Islamic counselor roles that help people develop and grow in a healthy relationship with God. In this context, people move from one level to the next, using life events as a means to personal growth and development. Applying knowledge found in the Holy Quran, this model of counseling seeks to place counseling in the context of personal, social and spiritual evolution. As we were conscious of this context, these values were embedded in our training. 
In summary, this was an exploratory study that aimed to introduce basic counseling skills to help preschool teachers in the state of Qatar to improve the quality of their relationships with themselves and with children. However, there are several limitations to the study that should be noted. First, the study focused on preschool teachers only. Second, the results cannot be generalized, as they do not correspond to the entire population of the Qatari society.

We found that teachers in Qatar receive little guidance on implementing counseling skills in schools. Moreover, in speaking to the more than 30 teachers (including the three teachers in this study) who attended the workshop, none of them has received prior training in guidance skills, despite the commitment to fostering teachers and school leaders in Qatari (SEC, 2007). It is stated:

"To create safe, supportive and challenging learning environments, the standards recognize that teachers and school leaders have a joint responsibility to develop effective learning environments in which students are safe, supported and intellectually challenged, both at classroom and whole-school levels." (p.2)

It appears that there has been little support or training in teacher guidance and counseling skills. As academics involved in the pre-service and in-service training of teachers, we are aware that much of the training priorities has focused on the training of subject matter standards. We are also aware that this training has evolved to support schools dealing with the reform elements (EFNE). Other aspects of the standards have been pushed aside, including those aspects that deal specifically with the psychological wellbeing of teachers and students.

The results demonstrate that there was quite a high level of improvement in the teachers' performance, based on the self-report rating and the data collected through observations and interviews. The teachers also agreed that listening is the most important skill when dealing with children. Teachers were interested in having more workshops and training in counseling skills in the future. Moreover, the results of the study show that the application of basic counseling skills helped the teachers to improve the quality of their relationships with themselves and others, and it helped them be aware of the children's needs.

\section{Conclusion and Implications}

The study assessed preschool teachers' relationships with their preschool students. The results demonstrate the need for using basic counseling skills with children at an early age. Several conclusions and implications can be derived from this study. The most important conclusion is that teachers need to be supported and provided with more workshops, guidance lectures and practical training in basic counseling skills to help the teachers work more effectively.

\section{Acknowledgement}

This publication was made possible by an Internal Grant [QUST CED EDU 1011 13] from the Qatar University. The statements made herein are solely the responsibility of the author[s].

\section{References}

Al-Rashidi, B. S. (1995) Self-Management: A Model of Counseling and Mental Health, Kuwait: Al Kuwait Publishing Bookshop.

Al-Shennawy, M. M. (2001). Studies in Islamic Guidance to Counseling Therapy. Cairo: Ghareeb House of Printing Publishing and Distribution.

Alsmadi, R., \& Mahasneh, R. (2011). Jordanian School Counselors' Leadership Behaviors. International Journal for the Advancement of Counseling, 33(3), 161-171. http://dx.doi.org/10.1007/s10447-011-9119-3

Al-Sulayti, H. (1999). Education and Training in GCC Countries: Some Issues of Concern. Education and the Arab World: Challenges for the Next Millennium. Abu Dhabi, UAE: The Emirates Centre for Strategic Studies and Research.

Ammari, S. (2004). The difficulties that hinder the counselors' performance of their counseling duties and its relation to gender, experience, type and size of school. Unpublished master's thesis, Arab Amman graduate studies university, Amman, Jordan.

Ashman, A. F. (2003). Peer mediation and students with diverse learning needs. In R.M. Gillies \& A. F. Ashman (Eds.), Co-operative Learning: The Social and Intellectual Outcomes of Learning in Groups (pp.87-102). London: Routledge Falmer.

Berry, J. O. (1987). A program for training teachers as counselors of parents of children with disabilities. Journal of Counseling and Development, 65(9), 508-509. http://dx.doi.org/10.1002/j.1556-6676.1987.tb00768.x 
Bowling, A. (2002). Research Methods in Health: Investigating Health and Health Services. Buckingham, Open University Press.

Bryman, A., \& Cramer, D. (2001). Social Research Methods. Oxford: University Press.

Central Intelligence Agency. (CIA). (2009). CIA World FactBook. Washington, D.C. Retrieved 8 July, 2010, from https://www.cia.gov/library/publications/the-world-factbook/geos/qa.html

Christensen, L., Young, R. K., \& Marchant, M. (2007). Behavioral intervention planning: Increasing appropriate behavior of a socially withdrawn student. Education and Treatment of Children, 30(4), 81-103.

Elias, M. J., \& Weissberg, R. P. (2000). Primary prevention: Educational approaches to enhance social and emotional learning. Journal of School Health, 70(5), 186-190. http://dx.doi.org/10.1111/j.1746-1561.2000.tb06470.x

Farsoun, S. (1985). Arab society: Continuity and change. Dover, New Hampshire: Croom Helm.

Feagin, Joe R., Anthony M. Orum., \& Gideon Sjoberg, eds. (1991). A Case for the Case Study. Chapel Hill: The University of North Carolina Press.

Hutchins, D. E., \& Vaught, C. C. (1997). Helping relationships and strategies (3rd ed.).Pacific Grove, CA: Brooks/Cole.

Kline, F. M., \& Silver, L. B. (2004). The Educator's Guide to Mental Health Issues in the Classroom. Baltimore: Maryland: Paul H. Brookes Publishing Company.

Kottler, J. A., \& Kottler, E. (1993). Teacher as Counselor: Developing the Helping Skills You Need. Newbury Park, CA: Corwin Press, Inc.

Lam, S., \& Hui, E. (2010). Factors affecting the involvement of teachers in guidance and counselling as a whole-school approach, British Journal of Guidance \& Counseling, 38(2), 219-234. http://dx.doi.org/10.1080/03069881003674962

Lane, L. K., Gresham, F. M., \& O'Shaughnessy, T. E. (2002). Interventions for Children With or At Risk for Emotional and Behavioral Disorders. Boston, MA: Allyn \& Bacon.

Matthews, D., \& Menna, R. (2003). Solving problems together: The importance of parent/school/community collaboration at a time of educational and social change. Education Canada, 43(1), 20-23.

Mayer, M., Lochman, J., \& Van Acker, R. (2005). Introduction to the special issue: Cognitive-behavioral interventions with students with EBD. Behavioral Disorders, 30(3), 197-212.

McLeod, J. (2003). Doing Counseling Research. London: Sage Publications.

McLeod, J. (2009). An Introduction to Counseling, $\left(4^{\text {th }}\right.$ ed.). Berkshire: Open University Press.

Mearns, D., \& Cooper, M. (2005). Working at Relational Depth in Counseling and Psychotherapy. London: Sage Publications.

Mearns, D., \& Thorne, B. (1999). Person-Centered Counseling in Action. London: Sage Publications.

Merry, T. (2004). 'Classical Client-Centered Therapy'. In Sanders, P. (ed.) The Tribes of The Person-Centered Nation: An Introduction to The Schools of Therapy Related to The Person-Centered Approach. Ross-on-Wye: PCCS BOOKS.

Merry, T., \& Lusty, B. (1993). What is Person-Centered Therapy? Loughton, Essex: Gale Centre Publications.

Nasser, R., \& Romanowski, M. (2011). Teacher Perceptions of Professional Development Training in Light of the National Educational Reform in Qatar. International Journal of Development and Training, 15(2), 158-168. http://dx.doi.org/10.1111/j.1468-2419.2011.00377.x

Palmer, B.C., El-Ashry, F., Leclere, J.T., \& Chang, S. (2007). Learning from Abdallah: A case study of an Arabic-speaking child in a U.S. school. The Reading Teacher, 61(1), 8-17. http://dx.doi.org/10.1598/RT.61.1.2

Pavri, S., \& Monda-Amaya, L. (2001). Social support in inclusive schools: Student and teacher perspectives. Exceptional Children, 67(3), 391-411.

Pirtle, T. N., \& Perez, P. (2003). Survival Counseling Skills for New Teachers (Report No. 5P041722). Texas A \& M International University. (ERIC Document Reproduction Service No. ED479644).

Rogers, C. R. (1961). On Becoming a Person: A Therapist's View of Psychotherapy. London, Constable. 
Schnitzer, G., Andries, C., \& Lebeer, J. (2007). Usefulness of cognitive intervention programs for socio-emotional and behavior problems in children with learning disabilities. Journal of Research in Special Education Needs, 7(3), 161-171. http://dx.doi.org/10.1111/j.1471-3802.2007.00093.x

Sjoberg, G., Williams, N., Vaughn T. R., \& Sjoberg, A., F. (1991). “Introduction.” In J. R. Feagin, A. M. Orum, and G. Sjoberg, eds., A Case for the Case Study, pp. 1-26. Chapel Hill: The University of North Carolina Press

Supreme Education Council. (2007). National Professional Standards for School Teachers \& Leaders. Retrieved on June 24, 2010, from http://www.english.education.gov.qa/content/resources/detail/4532

Watts, A.G., \& Kidd, J. M. (2000). Guidance in the United Kingdom: Past, present and future. British Journal of Guidance \& Counselling, 28(4), 485-502. http://dx.doi.org/10.1080/713652315

Wong, M., Rosemond, M. E., Stein, B. D., Langley, A. K., Katoaka, S. H., \& Nadeem, E. (2007). School-based intervention for adolescents exposed to violence. The Prevention Researcher, 14(1), 17-20. 